\title{
Characterization of bacterial endophytes from Myanmar medicinal plants for antimicrobial activity against human and plant pathogens
}

\author{
Ei Mon Myo ${ }^{\oplus 1^{*}}$, Chaw Ei Htwe Maung ${ }^{2}$, Khin Mar Mya ${ }^{3}$, Aye Aye Khai ${ }^{1}$
}

${ }^{1}$ Mycology Laboratory, Biotechnology Research Department, Ministry of Education, Kyaukse, Myanmar, ${ }^{2}$ Molecular Genetics Laboratory, Biotechnology Research Department, Ministry of Education, Kyaukse, Myanmar, ${ }^{3}$ Cell Culture Laboratory, Biotechnology Research Department, Ministry of Education, Kyaukse, Myanmar

\begin{abstract}
This research aimed to investigate the antagonistic activity of the bacterial endophytes from Myanmar medicinal plants. Thirty-one bacterial isolates were isolated from Myanmar medicinal plants: Tinospora cordifolia (Wild.) Miers., Catharanthus roseus G. Don., Tectona hamiltoniana Wall. and Boscia variabilis Collett \& Hemsl. (Capparaceae). Dual culture and agar well diffusion methods were used for antimicrobial assay. One endophyte from Catharanthus roseus and two bacterial isolates from Boscia variabilis Collett \& Hemsl. (Capparaceae) had not only the antibacterial activity towards the human pathogenic bacteria but also the antifungal activity against the plant pathogenic fungi. From $16 \mathrm{~S}$ rRNA sequencing, one strain from Catharanthus roseus G. Don. was Bacillus amyloliquefaciens DSM7 and two antagonistic strains from Boscia variabilis Collett \& Hemsl. (Capparaceae) were Bacillus subtilis subsp. subtilis str. 168 and Bacillus amyloliquefaciens DSM7, respectively. The best medium for the maximum production of the bioactive compounds was Bacillus medium supplemented with the $4 \%$ of starch and $0.3 \%$ of peptone for B. amyloliquefaciens DSM7 and B. subtilis subsp. subtilis str. 168 showed the maximum antimicrobial compounds production when it was incubated in the medium amended with $3 \%$ of starch and $2 \%$ of peptone. The optimum conditions for the the maximum production of the antimicrobial compound were the medium $\mathrm{pH}$ of 6 at $35^{\circ} \mathrm{C}$ after two days of incubation for B. amyloliquefaciens DSM 7 and $B$. subtitlis subsp. subtilis str. 168 secreted the maximum concentration of the bioactive compounds at $\mathrm{pH}$ 7.5 and $35^{\circ} \mathrm{C}$ on second day incubation period. In conclusion, the isolated endophytic bacteria showed the strong antimicrobial activity towards the pathogenic microbes and they could be used in medicine and agriculture as well.
\end{abstract}

Keywords: Antibacterial. Antifungal. Culture conditions. Endophytes. Medicinal plants.

\section{INTRODUCTION}

Myanmar belongs to with enormous biodiversity of medicinal plants. Among them, Tinospora cordifolia (Wild.) Miers., Catharanthus roseus G. Don., Tectona hamiltoniana Wall. and Boscia variabilis Collett \& Hemsl. (Capparaceae) have a wide array of bioactive principles and they have been proven medicinally important plants.

Endophytes are the microorganisms that live inside the plant tissues and they have the activity which can suppress the growth of human pathogenic bacteria and plant pathogens. They are symbiotic microbial organisms

\footnotetext{
*Correspondence: Ei Mon Myo. Mycology Laboratory, Biotechnology Research Department, Ministry of Education, Kyaukse, Myanmar. Phone: +95 9 402620730. E-mail: eimonmyo@gmail.com
}

that inhabit the interior of plants without causing an apparent harm to the host (Bandara, Seneviratne, Kulasooriya, 2006). Endophytes belong to diverse groups of bacteria and fungi (Hirsch, Braun, 1992). Because natural selection favors the evolution of beneficial endophytic strains, several endophytes were found to secret secondary metabolites that protect plants against insect pests, pathogenic organisms as well as herbivores (Saikkonen et al., 2004), thus, endophytes represent a promising source of novel, biologically active metabolites for pharmacological and agricultural applications (Dreyfuss, Chapela, 1994; Schulz et al., 2002). Biochemical research revealed that a wide variety of natural products can be obtained from endophytic microbes (Ahmed et al., 2012). Natural products from endophytic fungi were observed to inhibit many 
pathogenic organisms including bacteria, fungi, viruses and protozoans.

Medicinal plants are gaining global attention because the herbal drugs are most effective, easily available and with negligible side effects. The world population uses the medicinal plants in health care with homeopathy. It is important to note that some of the endophytic microorganisms can produce the same secondary metabolites as that of the plant thus making them a promising source of novel compounds (Ahmed et al., 2012). Although it has been known for a long time, their significance becomes evident only more recently when it was shown that they play specific roles as for instance, protecting the plant hosts against pathogens. Many endophytes have antimicrobial activity. (Seo et al., 2010) found that some endophytic bacteria isolated from young radishes can be used as biocontrol agents against human and plant pathogens.

Low yield, fungal attack, pathogenic microbial attack and biotic or abiotic stress are often the problems faced in agriculture sector both in developing and developed countries. The beneficial properties of endophytes can be exploited to tackle the issues related to cultivated crop plants and to provide further benefit in agricultural sector (Rosenblueth, Martínez-Romero, 2006).

Researchers have been studying the endophytic bacteria and fungi from the medicinal plants for the last many years. However, the antimicrobial activity of the endophytic bacteria from Myanmar medicinal plants used in this experiment has not yet been sufficiently researched. To our knowledge, this is the first study to use Myanmar medicinal plants mentioned here for evaluating the antimicrobial activity of the endophytic bacteria against the plant pathogens.

\section{MATERIAL AND METHODS}

\section{Sample collection from some medicinal plants}

Firstly, the leaf, bark and the stems of Tinospora cordifolia (Wild.) Miers. (Family: Menispermaceae, Genus: Tinospora), Catharanthus roseus G. Don. (Family: Apocynaceae, Genus: Catharanthus), Tectona hamiltoniana Wall. (Family: Lamiaceae, Genus: Tectona) and Boscia variabilis Collett \& Hemsl. (Capparaceae) (Family: Closteroviridae, Genus: Boscia) were collected from Kankaw, Kyaukse, Myanmar. Healthy plant leaf samples were selected and taken in order to avoid contamination by plant pathogens. Collected plant leaf samples were brought to the laboratory within 24 hours and processed for microbial isolation following guidelines of (Nalini et al., 2005). The surface decontamination method described by (Fisher, Petrini, Scott, 1992) was used with some minor changes. Firstly, they were washed with tap water and were immersed in $70 \%$ ethanol for 1-3 minutes, following soaking in aqueous $70 \%$ sodium hypochlorite for 3-5 minutes. And then, the parts of the plants were sterilized in 70\% ethanol for 2-5 minutes and finally rinsed with sterilized distilled water for 5 times. After all these steps, the plant samples were dried under aseptic condition $\left(40^{\circ} \mathrm{C}\right.$ in hot air oven) and kept for the continuous use.

\section{Isolation of the endophytes from the selected medicinal plants}

For isolation of the endophytic bacteria, the sterilized plant parts were rolled many times on one part of the culture plate and it was kept as the positive control and negative control was also kept without any swab to know whether the surface sterilization was complete or not. They were incubated on the various media such as nutrient medium, Bacillus medium, starch casein agar (SCA), water agar and Tap Water Yeast Extract medium (TWYE) at $35^{\circ} \mathrm{C}$ for two weeks. The colonies that appeared around the plant samples were picked up with a sterile needle. And then, the collected bacterial isolates were sub-cultured on the medium to get the pure colonies. The resulting pure isolates were kept in a sterile $20 \%$ glycerol solution at $-80^{\circ} \mathrm{C}$ for further study.

\section{Production of the hydrolytic enzymes of the bacterial endophytes}

Amylase activity was determined in well-established plate assay based on the appearance of clear zones around the bacterial isolates which were incubated on nutrient medium containing $1 \%$ starch. After $24 \mathrm{~h}$ of incubation at $35^{\circ} \mathrm{C}$, the plate was flooded with iodine solution which allowed the visualization of clear halos around the colonies (Kim, Yang, Kim, 2003)

The production of cellulase enzymes was assayed on indicator plates containing $0.5 \%$ carboxymethylcellulose (CMC). Plates were incubated at $35^{\circ} \mathrm{C}$ for $72 \mathrm{~h}$ and then they were stained with $1 \mathrm{~g} / \mathrm{L}$ Congo red solution for 30 min and were extensively washed with $0.9 \% \mathrm{NaCl}$. The formation of clear zones around the colonies indicated CMC degradation (Palumbo, Kobayashi, 2000).

The protease activity was studied by the nutrient medium containing $1 \%$ gelatin, following the spraying of the plate with $1 \%$ iodine after overnight incubation to see the clear zone around the colony. And, esterase activity was investigated on nutrient medium supplemented with 
tween 80 and the positive result was regarded as the appearance of a halo zone around the colony after 3 days of incubation (Mehmood et al., 1999).

\section{Study on antibacterial activity of the isolated bacterial endophytes}

The bacterial isolates were screened for the antimicrobial activity against the human pathogenic bacteria such as Salmonella typhi, Staphylococcus aureus, Escherichia coli, Enterococcus fecalis, Candida albican, Bacillus cereus and Pseudomonas aeruginosa by dual culture and agar well diffusion methods. Firstly, each endophytic bacterium isolate was cultured in SCA broth for two days and the pathogenic bacteria were inoculated in Muller Hinton Broth for six hours respectively. Then, each endophytic bacterial broth culture was centrifuged at $12,000 \mathrm{rpm}$ for 30 minutes to separate the pellet and supernatant. At that time, the pathogenic bacterial broth was swabbed on each Muller Hinton Agar plate and $100 \mu \mathrm{L}$ of the supernatant was added into each well of the plates which were punched. In this antibacterial assay, tetracycline was used as a positive control and distilled water was used as a negative control. After $24 \mathrm{~h}$ incubation period, the inhibition zone was measured and recorded the antimicrobial activity as zone diameter in milliliter. All the experiments were carried out in triplicate and repeated for three times to get the accurate data.

\section{Determination of the antifungal activity of the isolated bacterial endophytes}

The endophytic bacterial isolates were investigated for the antifungal activity against the plant pathogenic fungi by dual culture and agar well diffusion methods. Firstly, each endophytic bacterium isolate was cultured in SCA broth for three days and Rhizotonia solani, Fusarium oxysporum and Pythium sp., Metarhizium and other isolated plant pathogenic fungi were also inoculated in Potatoe Dextroxe Broth for three days respectively. Then, each bacterial broth culture was centrifuged at 12,000 rpm for 30 minutes and the supernatant was collected. The PDA plates were swabbed with the fungal broth and kept to dry for a few minutes. Then, the plates were punched and $100 \mu \mathrm{L}$ of the supernatant was added into each well of the plates which were swabbed with each pathogenic fungal broth. Nystatin dissolved in distilled water was used as a positive control. After 3 days of incubation at $25^{\circ} \mathrm{C}$, the inhibition zones were measured and recorded. The effective strains which show the antimicrobial activity were selected and continued to study.

\section{Characterization of the potent endophytic bacteria}

The three potent bacterial strains were characterized by morphological and biochemical tests according to Bergey's Manual of Systematic Bacteriology (Holt et al., 1986). The genomic DNA was extracted from each of potent bacterial strain and it was amplified by using polymerase chain reaction (PCR). The PCR cocktail consisting of distilled water $4.9 \mu \mathrm{L}$, Taq polymerase $0.3 \mu \mathrm{L}$, Taq buffer $1 \mu \mathrm{L}$, dNTPs $0.8 \mu \mathrm{L}$, genomic DNA $1 \mu \mathrm{L}, 10 \mathrm{~F}$ primer (5' CTACCAGGGTATCTAAT 3') $1 \mu \mathrm{L}$ and 800R primer (3'AGTTTGATCCTGGCTC 5') was used for amplification of $16 \mathrm{~S}$ rRNA gene fragment, and the size of the amplified DNA fragment was checked by $1 \%$ agarose gel electrophoresis by using $100 \mathrm{bp}$ DNA ladder. Then, the purified PCR products were sent to the company (Macrogen, South Korea) for $16 \mathrm{~S}$ rRNA sequencing. The alignment and assessment of the gene sequences data were performed by comparing with the sequences available in Gene Bank database of NCBI, using the algorithm BLAST program. Those sequences with highest identity were selected and aligned in the multiple-sequence alignment program, Clustal X (Thompson et al., 1997), and the phylogenetic tree was constructed according to Neighbour-joining method by MEGA 6.0 (Tamura et al., 2013).

\section{Optimum medium for the maximum production of bioactive compounds}

Three potent bacterial strains were inoculated into the different media such as Starch Casein Agar, Bacillus medium and nutrient agar at $35{ }^{\circ} \mathrm{C}$ for two days. Then, they were centrifuged at $12000 \mathrm{rpm}$ for $30 \mathrm{~min}$ and $100 \mu \mathrm{L}$ of each representative cell free supernatant was added into each well of the Muller Hinton agar and PDA plates which were swabbed with the human pathogenic bacteria and plant pathogenic fungi respectively. The antibacterial and antifungal activities were noted as inhibition zone in millimeter (Sierra, 1957).

\section{Incubation time for the optimum antimicrobial compounds production}

Each selected potent endophytic bacterium was inoculated in Bacillus medium broth at $35{ }^{\circ} \mathrm{C}$ for two weeks. At every $24 \mathrm{hr}$ interval, the flasks were harvested daily and they were centrifuged at $12000 \mathrm{rpm}$ for 30 minutes. And then, $100 \mu 1$ of the supernatant was taken and examined the antibacterial and antifungal activity by agar well diffusion method previously mentioned. 


\section{Carbon and nitrogen sources}

The isolated strains were incubated into the basal medium (Bacillus medium) supplemented with different carbon sources named sucrose, starch, dextrose, glucose and mannitol and various nitrogen sources such as peptone, $\mathrm{KNO}_{3}$, Casein, yeast extract and $\left(\mathrm{NH}_{4}\right)_{2} \mathrm{SO}_{4}$. For the optimum concentration of the carbon and nitrogen nutrients, different amounts of $0.15,0.3,0.5,1,1.5,2,2.5$, $3,3.5,4,4.5$ and $5 \%$ of each carbon and nitrogen sources were added into the basal medium (Haggag, El Soud, 2012) and they were incubated at $35^{\circ} \mathrm{C}$ for three days. And then, the antibacterial and antifungal activities of each collected supernatant were examined by agar well diffusion method.

\section{$\mathrm{pH}$ and temperature}

For the optimum $\mathrm{pH}$ examination, Bacillus medium was used with different $\mathrm{pH}$ of $3,4,5,6,7,8,9,10,11$ and 12 and the optimum temperature was also studied from the range of 15 to $50{ }^{\circ} \mathrm{C}$ at the difference of $5{ }^{\circ} \mathrm{C}$ for three endophytic bacteria (Merlin et al., 2013). The antimicrobial and antifungal activities were also studied against human pathogenic bacteria and plant pathogenic fungi by agar well diffusion method. All the experiments were done in three replicates for three times to obtain the accurate and specific data.

\section{RESULTS AND DICUSSION}

\section{Isolation of endophytes from the selected medicinal plants}

Total thirty one bacterial strains was isolated from the four medicinal plants. Six bacterial strains were obtained from Tinospora cordifolia (Wild.) Miers., another six different strains were discovered from Catharanthus roseus $G$. Don., five potent bacterial endophytes were isolated from Tectona hamiltoniana Wall. and fourteen bacterial strains were obtained from Boscia variabilis
Collett \& Hemsl. (Capparaceae). Although other fungal strains also appeared on the SCA and TWYE media, they were not collected for this experiment because this research was aimed to investigate the antimicrobial activity of the endophytic bacteria.

\section{The hydrolytic enzyme producing activity of microbes}

From this experiment, it was found that almost all of the endophytes had the protease and amylase producing activities. But, these isolated bacteria did not show the potent activity for degradation of cellulose and they did not not have esterase activity as well. So, it can be assumed that these endophytic bacteria can also be applied in food, detergent, and cosmetic industries that use the protease and amylase enzymes.

\section{Antibacterial activity of the endophytes against the human pathogenic bacteria}

After studying the antimicrobial activity of the isolated strains against the human pathogenic bacteria by dual culture method and agar well diffusion method, it was found that all the isolated endophytes did not have the antagonistic activity. From the total thirty one isolated bacteria, one microorganism isolated from Catharanthus roseus $G$. Don. and four bacterial strains from Boscia variabilis Collett \& Hemsl. (Capparaceae) had the activity which can inhibit the growth of the human pathogenic bacteria and plant pathogenic fungi. As illustrated in Table I, TB3, TM12 and TM13 had the best antibacterial activity among the isolated bacterial endophytes, nearly $20 \mathrm{~mm}$ in zone diameter on the plate.

\section{Antifungal Activity of the endophytic bacteria isolated from the medicinal plants}

Antifungal activity of the isolated bacteria was also investigated daily by dual culture and agar well diffusion

TABLE I - Antibacterial activity of the isolated bacterial strains against the human pathogenic bacteria (Zone diameter in mm)

\begin{tabular}{lcccc}
\hline Endophytes & P. aeruginosa & S. aureus & S. typhi & B. cereus \\
\hline TB3 & 17 & 18 & 20 & 20 \\
TM9 & 10 & 13 & 10 & 15 \\
TM12 & 18 & 20 & 20 & 20 \\
TM13 & 20 & 18 & 20 \\
TM14 & 18 & 20 & 15 & 20 \\
\hline
\end{tabular}


Characterization of bacterial endophytes from some important myanmar medicinal plants

TABLE II - Antifungal activity of the isolated bacterial endophytes against the plant pathogenic fungi (Zone diameter in $\mathrm{mm}$ )

\begin{tabular}{lccccc}
\hline Endophytes & Metarhizium & Pythium sp. & Or 3.2 & PF1 & PF4 \\
\hline TB3 & 25 & 23 & 25 & 35 & 30 \\
TM9 & 14 & 15 & 16 & 32 & 15 \\
TM12 & 26 & 23 & 28 & 32 & 35 \\
TM13 & 24 & 23 & 20 & 35 & 35 \\
TM14 & 24 & 20 & 25 & 32 & 35 \\
\hline
\end{tabular}

methods. Among the five antagonistic strains, TB3, TM12, and TM13 showed the greatest antifungal activity against the four target plant pathogenic fungi and the data were illustrated in Table II. These strains had better antifungal activity against the pathogenic fungi isolated from the infected potato (about $35 \mathrm{~mm}$ in diameter).

\section{Identification of the endophytic bacteria}

Total base nucleotide of 16S rRNA gene sequences was analyzed by multiple alignments using Clustal X of MEGA 6 program. Based on the phylogenetic tree and 16S rRNA sequencing, the nearest homolog genus-species with the beneficial strain isolated from Catharanthus roseus G. Don. was found to be $97 \%$ similarity to Bacillus amyloliquefaciens DSM7 and two bacterial isolates from Boscia variabilis Collett \& Hemsl. (Capparaceae) had 99\% identity with Bacillus amyloliquefaciens DSM7 and Bacillus subtilis subsp. subtilis str. 168 respectively. Their evolutional relationship with other Bacillus species was illustrated in Figure 1.

\section{Cultural optimization of endophytic bacteria for fermentaion processes}

From this study, it was clearly seen that Bacillus medium was the best medium for optimum antimicrobial compound production.

The optimum secondary metabolite production of each selected bacterium was investigated daily for two weeks. All of three strains isolated from Myanmar medicinal plants showed the most efficient antimicrobial and antifungal activities with their growth in Bacillus medium and it was seen that the optimum incubation time for the production of the bioactive compounds was two days of incubation for antimicrobial activity and antifungal activity was the optimum after three days of fermentation (Figure 2).

The best carbon and nitrogen sources for the maximum production of the antimicrobial compound were also studied. All the endophytic strains gave the

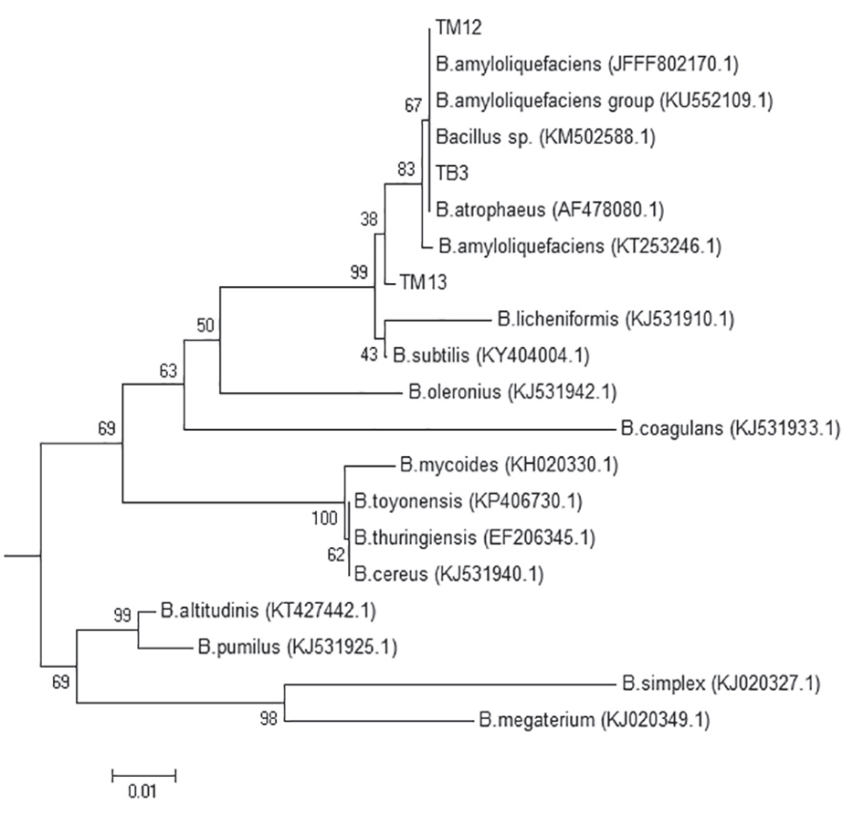

FIGURE 1 - Evolutionary relationships of taxa. The evolutionary history was inferred using the Neighbor-Joining method. The optimal tree with the sum of branch length = 0.36747719 is shown. The percentage of replicate trees in which the associated taxa clustered together in the bootstrap test (1000 replicates) are shown next to the branches. The tree is drawn to scale, with branch lengths in the same units as those of the evolutionary distances used to infer the phylogenetic tree. The evolutionary distances were computed using the Maximum Composite Likelihood method and are in the units of the number of base substitutions per site. The analysis involved 20 nucleotide sequences. All positions containing gaps and missing data were eliminated. There were a total of 363 positions in the final dataset. Evolutionary analyses were conducted in MEGA6.

optimum antimicrobial activity against plant and human pathogens when they were inoculated in the basal medium with starch and peptone (Figure 3). From the maximization of the carbon and nitrogen concentration, it was found that $3.5-4 \%$ of starch and $0.3 \%$ of peptone for B. amyloliquefaciens DSM7 from Boscia variabili was the optimum composition for the production of the antimicrobial compounds and it was shown in Figure 4. 

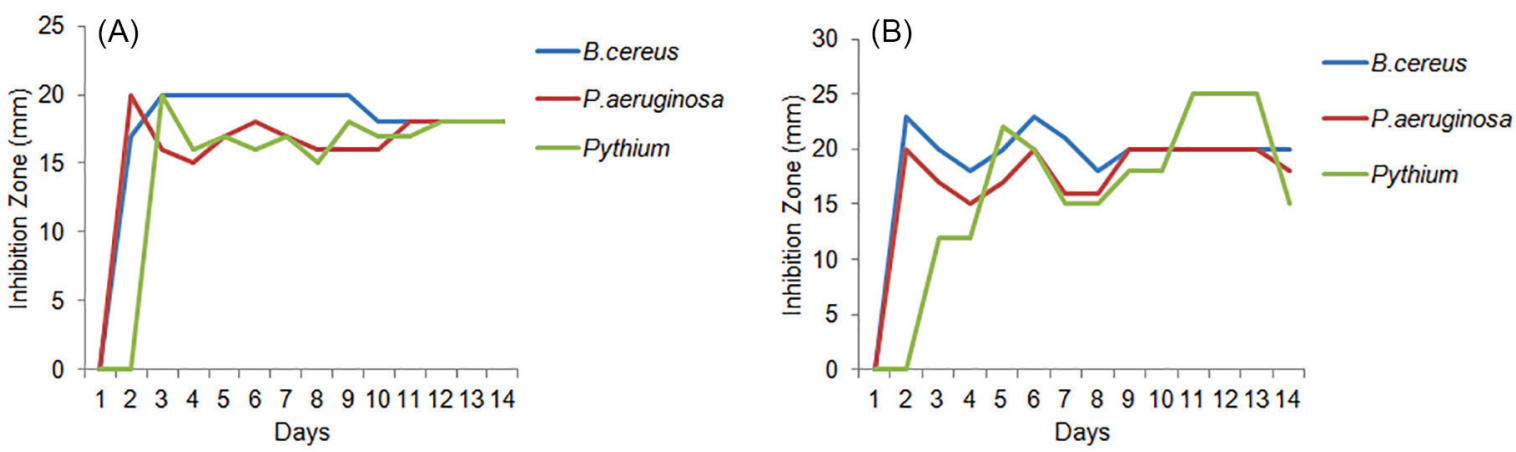

FIGURE 2 - Antimicrobial activity of the bacterial endophytes against B. cereus, P. aeruginosa, and Pythium at different incubation periods (A) B. amyloliquefaciens DSM7 (B) B. subtilis subsp. subtilis str. 168
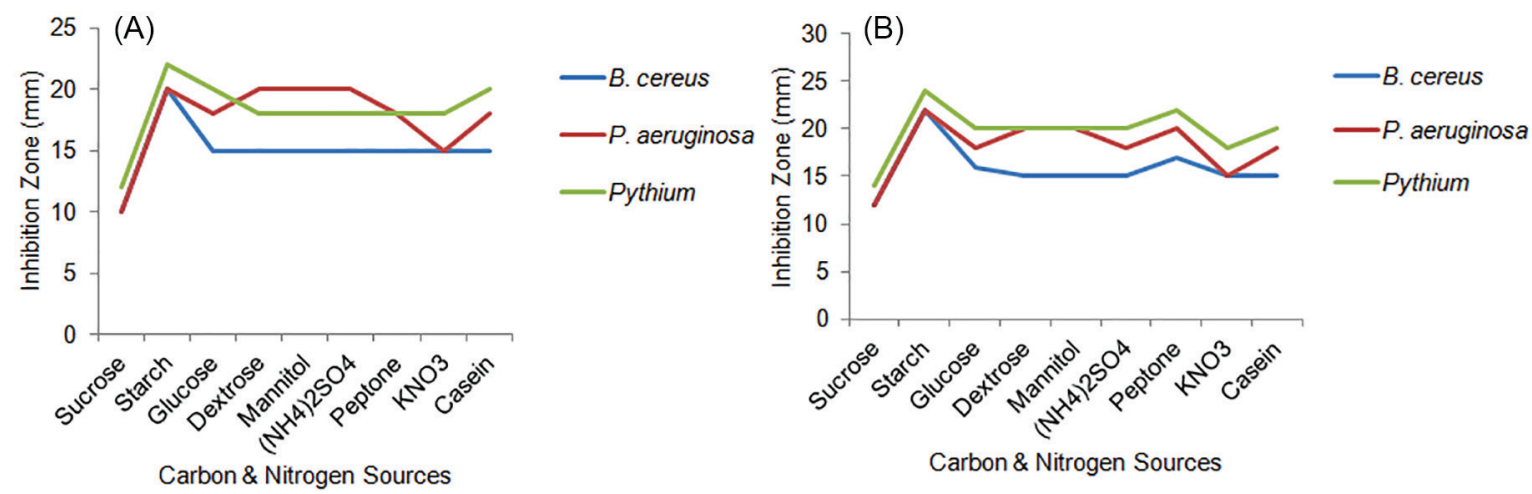

FIGURE 3 - The effect of carbon and nitrogen sources on the antimicrobial activity of the endophytes against $B$. cereus, P. aeruginosa, and Pythium (A) B. amyloliquefaciens DSM7 (B) B. subtilis subsp. subtilis str. 168
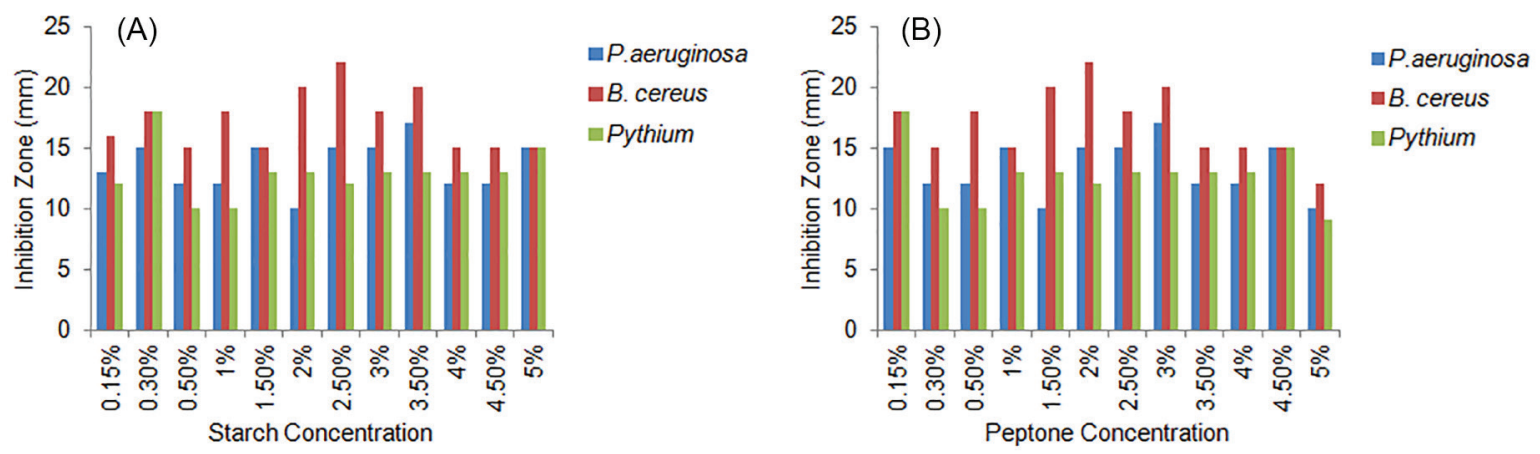

FIGURE 4 - The effect of starch and peptone compositions on the antimicrobial activity of B. amyloliquefaciens DSM7 against different pathogens.
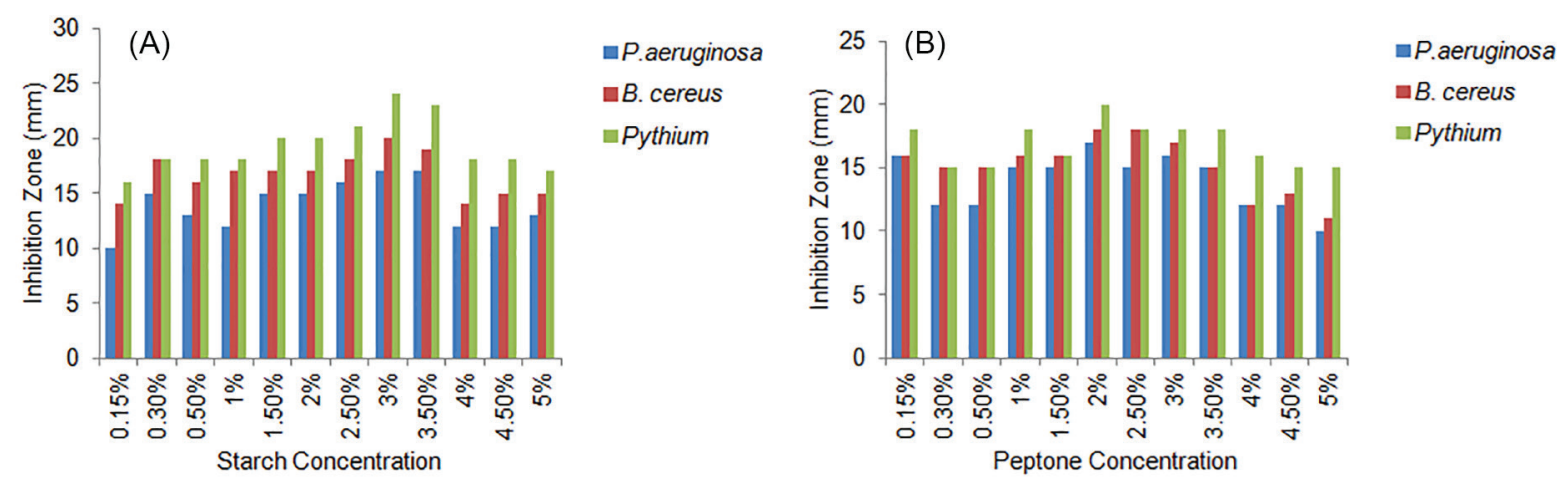

FIGURE 5 - The effect of starch and peptone compositions on the antimicrobial activity of $B$. subtilis subsp. subtilis str. 168 against different pathogens. 

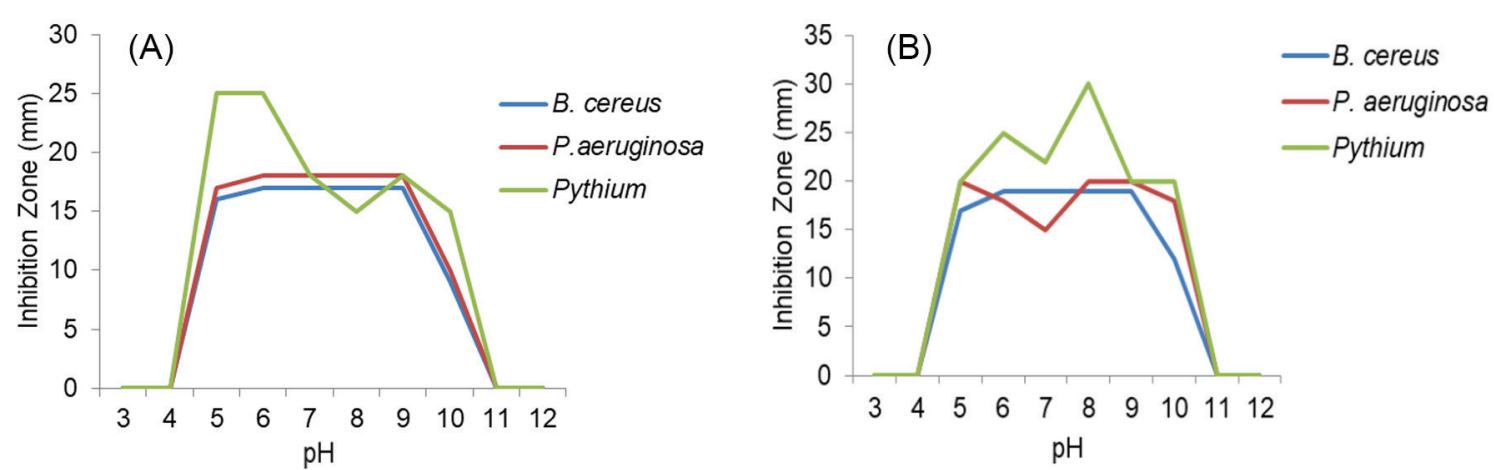

FIGURE 6 - The effect of $\mathrm{pH}$ on the antimicrobial activity of B. amyloliquefaciens DSM7 and B. subtilis subsp. subtilis str. 168 against B. cereus, P. aeruginosa, and Pythium (A) B. amyloliquefaciens DSM7 (B) B. subtilis subsp. subtilis str. 168.
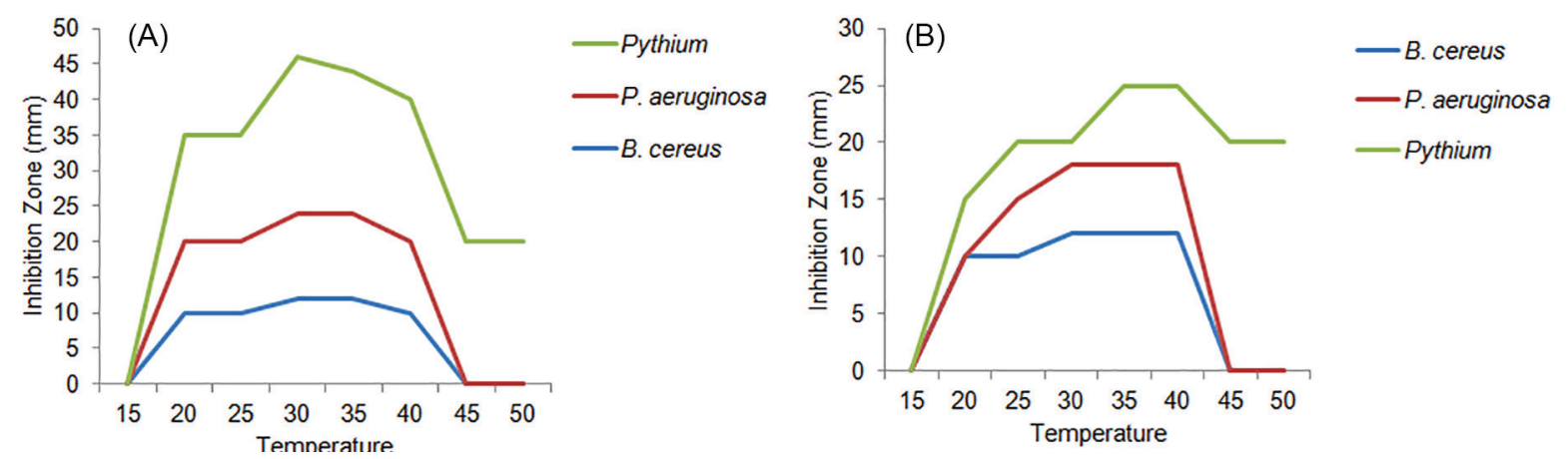

FIGURE 7 - The effect of temperature on the antimicrobial activity of B. amyloliquefaciens DSM7 and B. subtilis subsp. subtilis str. 168 against B. cereus, P. aeruginosa, and Pythium (A) B. amyloliquefaciens DSM7 (B) B. subtilis subsp. subtilis str. 168

And then, B. subtilis subsp. subtilis str. 168 secreted the maximum amount of secondary metabolites into the medium supplemented with $3 \%$ of starch and $2 \%$ of peptone respectively (Figure 5).

\section{The effect of $\mathrm{pH}$ and temperature on the production of antimicrobial compounds}

The optimum $\mathrm{pH}$ for maximum production of the antimicrobial compounds by B. amyloliquefaciens DSM7 was 7.5 and B. subtilis subsp. subtilis str. 168 had the strongest antimicrobial activity at $\mathrm{pH} 6$ (Figure 6). Both of these two strains did not show the antifungal activity at $\mathrm{pH} 3$ and 4 and so it could be discussed that the beneficial endophytic strains could not produce the secondary metabolites for antimicrobial and antifungal activities in acidic condition. In concern with the temperature, $B$. amyloliquefaciens DSM7 showed the optimum temperature at $30-35^{\circ} \mathrm{C}$ and $B$. subtilis subsp. subtilis str. 168 had the optimum antimicrobial compounds producing activity if it was inoculated at $35^{\circ} \mathrm{C}$ (Figure 7). Both of these two strains did not show the antimicrobial activity against the human pathogens and plant pathogens at $15^{\circ} \mathrm{C}$ incubation because they could not completely grow at this temperature. And, although both strains did not have the antibacterial activity against the human pathogenic bacteria if they were incubated at $45^{\circ} \mathrm{C}$ and $50{ }^{\circ} \mathrm{C}$, they still produced the antifungal compounds at these temperatures.

\section{CONCLUSION}

The main conclusion that can be drawn was that two Myanmar medicinal plants named Catharanthus roseus G. Don. and Boscia variabilis Collett \& Hemsl. (Capparaceae) consisted of the effective endophytic bacteria which could secrete the bioactive compounds (secondary metabolites), which can suppress both the human pathogenic bacteria and the plant pathogenic fungi. And, these beneficial endophytic strains could be used not only in medical field but also in agriculture as biofungicide. Since they were isolated from the medicinal plants, it was clearly concluded that they will not give the side effects to humans by using them.

\section{THE AUTHORS' CONFLICT}

The author(s) declear(s) that there is no conflict of interest regarding the publication of this paper. 


\section{ACKNOWLEDGEMENTS}

This research was supported by Biotechnology Research Department (BRD), Ministry of Education, Kyaukse, Myanmar. The author really appreciates to Dr. Aye Aye Khai, Director of BRD for supporting this research. And, the sincere thanks are also due to her colleagues from Mycology Lab for their kind helps.

\section{REFERENCES}

Ahmed M, Hussain M, Dhar MK, Kaul S. Isolation of microbial endophytes from some ethnomedicinal plants of Jammu and Kashmir. J Nat Prod Plant Resour. 2012;2(2):215-20.

Bandara W, Seneviratne G, Kulasooriya SA. Interactions among endophytic bacteria and fungi: effects and potentials. J Biosci. 2006;31(5):645-50.

Dreyfuss M, Chapela IH. Potential of fungi in the discovery of novel, low-molecular weight pharmaceuticals. Discovery of novel natural products with therapeutic potential. Biotechnology. 1994;26:49-80.

Fisher P, Petrini O, Scott HL. The distribution of some fungal and bacterial endophytes in maize (Zea mays L.). New Phytol. 1992;122(2):299-305.

Haggag WM, El Soud MA. Production and optimization of Pseudomonas fluorescens biomass and metabolites for biocontrol of strawberry grey mould. Am J Plant Sci. 2012;3(7):836.

Hirsch G, Braun U. Communities of parasitic microfungi. Fungi in vegetation science Netherlands: Springer; 1992. p.225-250.

Holt J, Krieg N, Sneath P, Staley J. Bergey's manual of systematic bacteriology. Baltimore: Williams and Wilkins; $1986 ; 2$.

Kim K-J, Yang Y-J, Kim J-G. Purification and characterization of chitinase from Streptomyces sp. M-20. J Biochem Mol Biol. 2003;36(2):185-9.

Mehmood Z, Ahmad I, Mohammad F, Ahmad S. Indian medicinal plants: a potential source for anticandidal drugs. Pharm Biol.1999;37(3):237-242.
Merlin JN, Christhudas I, Kumar PP, Agastian P. Optimization of growth and bioactive metabolite production: Fusarium solani. Asian J Pharm Clin Res. 2013;6(3):98-103.

Nalini MS, Mahesh B, Tejesvi MV, Prakash HS, Subbaiah V, Kini KR, et al. Fungal endophytes from the three-leaved caper, Crataeva magna (Lour.) DC.(Capparidaceae). Mycopathologia. 2005;159(2):245-9.

Palumbo J, Kobayashi D. Bacterial endophytes and their effects on plants and uses in agriculture. Microbial Endophytes. Boca Raton: CRC Press; 2000. p.213-50.

Rosenblueth M, Martínez-Romero E. Bacterial endophytes and their interactions with hosts. Mol Plant Microbe In. 2006;19(8):827-37.

Saikkonen K, Wäli P, Helander M, Faeth SH. Evolution of endophyte-plant symbioses. Trends Plant Sci. 2004;9(6):27580.

Schulz B, Boyle C, Draeger S, Römmert AK, Krohn K. Endophytic fungi: a source of novel biologically active secondary metabolites. Mycol Res. 2002;106(9):996-1004.

Seo WT, Lim WJ, Kim EJ, Yun HD, Lee YH, Cho KM. Endophytic bacterial diversity in the young radish and their antimicrobial activity against pathogens. J Korean Soc Appl Biol Chem. 2010;53(4):493-503.

Sierra G. A simple method for the detection of lipolytic activity of micro-organisms and some observations on the influence of the contact between cells and fatty substrates. Anton Leeuw. 1957;23(1):15-22.

Tamura K, Stecher G, Peterson D, Filipski A, Kumar S. MEGA6: molecular evolutionary genetics analysis version 6.0. Mol Biol Evol. 2013;30(12):2725-9.

Thompson JD, Gibson TJ, Plewniak F, Jeanmougin F, Higgins DG. The CLUSTAL_X windows interface: flexible strategies for multiple sequence alignment aided by quality analysis tools. Nucleic Acids Res. 1997;25(24):4876-82.

Received for publication on $14^{\text {th }}$ November 2017 Accepted for publication on $17^{\text {th }}$ October 2018 